\title{
Commitment to Action
}

\author{
Marvin L. Birnbaum, MD, PhD
}

Life is not void of scorners:

We bave laughed loud and kept our love, We have heard singers in tavern corners And have not forgotten the birds above: We bave known smiters and sons of thunder And not unworthily walked with them, We have grown wiser and lost not wonder.....

\section{G.K. Chesterton}

As is evidenced from just a glance at the Abstracts of the Scientific and Invited Papers for the 11th World Congress on Disaster and Emergency Medicine included as a Supplement to this issue of Prehospital and Disaster Medicine, the scope of Prehospital, Emergency, and Disaster Medicine is vast. I do not recall as broad a representation of topics as will be presented in Osaka. Hats off to our colleagues in Japan who have assembled such a remarkable set of papers and discussions.

Further, the bulk of the presentations will be provided by scientists from the Asia-Pacific region. This is a testament to the active interest and energy of the scientists in this region. Indeed, there is a great deal of good, solid research and study being done in Emergency and Disaster Medicine. Our discipline is expanding, our science is evolving, and our understanding of the dynamics of our practice is growing at an exponential rate. I applaud all of you working in this exciting, new field.

This work takes on even greater importance and relevance in light of the dreadful events occurring in the world. Special attention must be given to the statements of Dr. Rottman in his Presidential Address (page s14). We have a moral and professional responsibility to become involved in the mitigation of these preventable, human disasters.
Each of us must wonder, "What difference can one person make?" We come together in World and Regional Congresses to learn from what others have learned; we do not learn what is known about Disaster and Emergency Medicine from our self-experiences. We must share our experiences in order to learn to practice our particular kind of medicine.

We all are repulsed by the inhumane events currently occuring on our world. We recognize that we have both a medical and moral obligation to try to intervene. But, alone, or even in small groups, we are impotent in affecting world events. Although important and essential, our medical interventions seem relatively meager in terms of an overall impact. Yet, we want to help. Each of us is drawn in. Each of us asks, "What can I do?" "What can WE do?"

Like with our need for scientific knowledge that draws us together in Congresses and motivates us to subscribe to this Journal, we must combine our energies to exert a significant influence on world events. We must coordinate and combine our efforts. We have great knowledge and skills. We know more than anyone else about the potential and actual role of Medicine in these events.

There are many reports in the Supplement that detail the important contributions of individual national organizations in ameliorating the impact of disasters worldwide. The motivation always has been and will continue to be prevention and alleviation of human suffering. Special attention is given to complex emergencies and the role of individual organizations in providing medical care to the innocent victims. There also is much discussion about the special problems of the children (see accompanying editorial by Dr. Roshal). Dr. Roshal continues his drive to form an international organization to respond to the special needs of children in these horrendous emergencies. But, his philosophy must be extended to all of Disaster Medicine. To make an impact, our efforts must be combined and coordinated.

Despite recognition of the problems, no one organization assumes the responsibility for command and coordination of international medical efforts when they are needed. Two facts became clear during the recent meeting in Santo Domingo in March sponsored by the Pan-American Health Organization, the World Health Organization, and the United Nations to evaluate the effectiveness of the responses to Hurricanes Georges and Mitch: 1) there was little centralized, overall coordinating mechanism utilized in most of the countries impacted; and 2) where there was organization, as exemplified by the PanAmerican Health Organization's (PAHO's) mechanism for organizing and distributing supplies, SUMA, as implemented in Nicaragua, coordinated responses gained substantially in efficiency, efficacy, and impact over those that were not so well organized and directed. The most significant message from digestion of the events and responses surrounding the impact of Hurricanes Georges and Mitch was the uniform and repeated demand for designated Coordination and Control.

The same message has become clear to me in two other recent forums: 1) the WADEM Steering Committee activities producing the Guidelines for the Study and Evaluation of Medical Responses to Disasters (to be published in the next issue of PDM); and 2) the Washington meeting, "Developing a Common Agenda to Reduce Risks from Natural Disasters: Public Health in Natural Disasters," 
in which representatives of WADEM met with medical and non-medical disaster organizations (governmental and non-governmental) to discuss potential interactions and the work of the numerous organizations participating in prevention of disasters and mitigation of the impact of events that may result in disasters. In both multidisciplinary forums, the WADEM has been the primary representative of Medicine.

Once again, it is clear that there is an over-riding need for coordination of our practices, just as there is an overriding need for assimilating the masses of information in our field that will be shared at Osaka and in this publication. Through this Journal and the conduct of international Congresses such as will occur in Osaka and as occurred in Costa Rica and the ISOHEIL meeting in Amsterdam within the past year, the WADEM is viewed as the logical representative of the World Medical Community in the area of Disaster and Emergency Medicine.

The WADEM should assume this role in earnest. We must demand that our leadership take an active role in the prevention and mitigation of the effects of such events. But, the leadership cannot do it alone. We all must dedicate ourselves to promulgation of what we all know is right. Separately, we make only a small dent in the Big Picture. Together, we have the power to make a profound impact.

Look beyond where and who you are and what you feel you must do. Now more than ever in the history of mankind, we have the opportunity to act and impact the Big Picture. We are one community; we have common dreams and goals. We must gather our energies and abilities and become active. We can have a profound impact, since it is assumed that the medical care for the victims of such catastrophes always will be present and adequate. We must establish the important role and responsibilities that go with our very name. Let us commit ourselves to this cause before we leave Osaka. The world is crying out for our help!

Dare to be wise: Begin! He who postpones the hour of living rightly is like the rustic who waits for the river to run out before he crosses it, yet on it glides, and will glide on forever.

Horace, Epistles 